J. RADIAT. RES., SUPPLEMENT, 378-384 (1991)

A Review of Forty-Five Years Study of Hiroshima and Nagasaki Atomic Bomb Survivors

III. FUTURE PERSPECTIVE

\title{
Biochemical Genetics Study
}

\author{
CHIYOKO SATOH
}

Department of Genetics, Radiation Effects Research Foundation,

Hiroshima and Nagasaki, Japan

DNA/RNA/Denaturing gradient gel electrophoresis/Polymerase chain reaction/Cell lines of B-lymphocytes

After 40 years of studies on the children of atomic bomb survivors and a suitable control population in which no statistically significant genetic effects of A-bomb radiation were observed, two new projects have been initiated in order to detect mutations in the DNA and RNA molecules. Permanent cell lines from peripheral B-lymphocytes from approximately 500 families composed of exposed parents and their children and approximately 500 control families are being established by Epstein-Barr virus transformation. Cells will be sources for DNA and RNA samples in the screening for mutations. After comparison of efficiencies of the scanning techniques, we selected the denaturing gradient gel electrophoresis (DGGE) of DNA fragments amplified by polymerase chain reaction (PCR) for our purpose. A small scale pilot study has started to solve problems and obtain a better efficiency in this approach. Current thinking about the most efficient procedures is presented.

\section{INTRODUCTION}

Extensive studies on the children of survivors of the atomic bombings of Hiroshima and Nagasaki have thus far yielded no statistically significant increases in genetic effects compared to a control population ${ }^{1)}$. With particular reference to biochemical studies ${ }^{2,3)}, 13,544$ children of proximally exposed parents whose gonad dose was $\geqq 0.01 \mathrm{~Sv}$ using RBE for neutrons of 20 and 10,117 children of distally exposed parents whose gonad dose was $<0.01 \mathrm{~Sv}$ were screened for de novo mutations of 30 blood proteins by one dimensional gel electrophoresis. Two and four mutations resulting in altered mobility were detected for the former and the latter groups, respectively. A subset of the children, 4,989 of the former and 5,026 of the latter, was further screened for loss of activity in nine erythrocyte enzymes. One mutation was detected in the former but none in the latter. When these two series were combined, there were three mutations in 727,936 locus tests for the former and four in 528,620 for the latter. Thus, mutation rate per locus per generation for the former was $0.41 \times 10^{-5}$ with $95 \%$ confidence interval between 0.09 and $1.20 \times 10^{-5}$, and that for the latter was $0.76 \times 10^{-5}$ with $95 \%$ confidence interval between 0.21 and $1.94 \times 10^{-5}$.

Because of the importance of exhausting all possible approaches to the genetic evaluation of these children and expectation that new and powerful techniques to detect mutations will be available in the future at a time when the A-bomb exposed parents and their children are no longer available, two projects have been carried out since 1985 . The one is establishing permanent 
cell lines from A-bomb survivors and their children and the other is introduction and development of technologies for screening for mutations in these children at the DNA and/or RNA level.

\section{EST ABLISHMENT OF CELL LINES}

The major portion of the children in the project have already cooperated in the previous biochemical genetics study for mutations at the protein level. Both of their parents were alive and younger than 65 in January, 1985 and they, at least one of them, have frequently cooperated in the Adult Health Study Program of the RERF. With these conditions for selection, a high cooperation rate is expected. Four groups of families are selected on the basis of parental dose. Group 1 consists of 305 families in which one or two parents were exposed to 2 Gy or more; the sampling ratio is $100 \%$. Group 2 consists of 305 families in which one or two parents were exposed to 1.99-1 Gy. Group 3 consists of 305 families in which one or two parents were exposed to $0.99-0.01 \mathrm{~Gy}$. Group 4 consists of 610 families in which one or two parents were exposed to less than $0.01 \mathrm{~Gy}$ and serve as the controls. The total number of families is 1,525 and an expected cooperation rate of $70 \%$ will give us approximately 1,000 families for this project.

Permanent cell lines are being established by using Epstein-Barr virus transformation from peripheral B-lymphocytes from family groups consisting of father, mother, and all available children (the minimum unit to be trios). They are allowed to proliferate approximately 500 -fold $\left(1 \times 10^{9}\right.$ cells) and cryopreserved in liquid nitrogen. Intact lymphocytes and polymorphonuclear cells are also preserved in liquid nitrogen in order to examine their DNAs or RNAs whenever somatic mutation is suspected. To date, cell lines have been established from 1,810 individuals from Hiroshima and Nagasaki which include 535 trios. The rate of establishing cell lines at present is approximately 120 trios per year and this rate will be continued or hoped to be increased to 150 .

\section{DETECTION OF MUTATIONS IN DNA AND RNA MOLECULES}

For our study determining nucleotide mutation rates, it is necessary to choose a method which can examine as many nucleotides as possible in one examination. After precise comparative examinations on $\beta$-globin genes ${ }^{4-6)}$ and consideration on accumulated data on genes encoding human (coagulation) factor IX, triosephosphate isomerase and phosphoglycerate kinase, we concluded that the denaturing gradient gel electrophoresis (DGGE) of DNA:DNA duplexes produced by amplification of genomic DNA fragments with polymerase chain reaction (PCR) ${ }^{7,8)}$ is the most effective technique to detect variations in DNA molecules among various scanning techniques such as the ribonuclease cleavage of mismatches in RNA:DNA duplexes ${ }^{6,9,10)}$, DGGE of RNA:DNA duplexes ${ }^{5}$, DGGE of DNA:DNA heteroduplexes ${ }^{11-14)}$ and chemical cleavage of mismatched base pairs ${ }^{15,16)}$.

In a parallel DGGE which is suitable for a large scale study such as ours, DNA:DNA duplexes of approximately 500 base pairs $(\mathrm{bp})$ which are suitable to detect nucleotide substitutions are electrophoresed on a gel in which denaturant concentration increases from the top to the bottom of the gel, the direction of electrophoresis being parallel with that of the denaturant gradient. 
Denaturing characteristics or melting behavior of the duplexes depends on the nucleotide sequences ${ }^{17)}$ and duplexes of approximately $500 \mathrm{bp}$ consists of two to four melting domains. When a duplex comes to the position where the concentration of denaturant is enough to denature the lowest melting domain of the duplex, the domain starts to denature and mobility of the duplex decreases. A duplex with a mismatch starts melting where the concentration of denaturant is much smaller compared to the duplex without a mismatch. Though DGGE will not separate DNA fragments with nucleotide substitutions in the highest temperature melting domains due to loss of sequence-dependent gel migration upon complete separation from the normal counterparts, the limitation were overcomed by addition of a high-temperature melting $\mathrm{G}+\mathrm{C}$-rich sequence (GC-clamp) to the test fragment ${ }^{18,19)}$.

A homozygote for a normal or a variant allele shows a single band of a duplex whose double strands are completely complementary to each other (homoduplex) but a heterozygote for a normal and a variant alleles shows four bands, that is, one normal homoduplex, one variant homoduplex and two types of heteroduplexes with mismatches one of which is produced by hybridization of a normal sense DNA strand with a variant antisense DNA strand and the other produced by hybridization of the opposite combination of the DNA strands. We confirmed that the DGGE can detect not only nucleotide substitutions but also small deletions and insertions of fragments less than 15 nucleotides ${ }^{20)}$.

In our approach, a target sequence of approximately $3,000 \mathrm{bp}$ is amplified by the $\mathrm{PCR}^{21-23)}$, cleaved into four to six fragments of approximately $500 \mathrm{bp}$ and examined by the DGGE. One of the most valuable characteristics of this method is that the most effective fragmentation for the detection of variations in a target sequence can be chosen by digestion with a combination of certain restriction enzymes considering the melting map ${ }^{24)}$ of the target sequence after PCR amplification. One can examine approximately 3,000 bp in one experiment instead of approximately $500 \mathrm{bp}$ which can be examined by the other scanning methods. The amount of chromosomal DNA sample is less than $1 / 10$ of that necessary for the other methods and the success rate for obtaining gels with good patterns is more than $95 \%$. In addition, since samples are PCR amplified genomic DNA fragments and bands on a gel are visualized by ethidium bromide, no probes nor radioisotopes are necessary. All of these make the workload and the analysis time necessary for this method minimum among those of the scanning methods.

Efforts are being made to introduce a multiple-targets system. Multiple targets amplified from a DNA sample with multiple primers will be examined in a single gel lane. Not only efficiency of a single examination will increase but also a total amount of the DNA sample from a single individual necessary for the screening will decrease employing the multiple-targets system. The possibility of increasing the detectability of the DGGE for variations in DNAs by addition of the GC-clamp to the test fragment is also being examined. This addition is easily carried out in the $\mathrm{PCR}^{7,8)}$. For certain kinds of genes, variations in RNA molecules will be examined. Our technique has been successfully applied to detection of variations in mRNAs after their conversion to single stranded complementary DNAs with reverse transcriptases ${ }^{25,26)}$.

A pilot study to examine 100 children from 63 families employing this technique is now under way. A very tentative estimate at present for the efficiency of the approach employing the three targets-system is approximately $2.5 \times 10^{8} \mathrm{bp} /$ technician/year for the total workload for screening, 
sequencing of mutants, and all other necessary work such as primer synthesis and extraction of DNA from cells. A more accurate value will be obtained after the data on several genes are accumulated in this pilot study.

Considering the predominance of radiation induced deletional gene mutations ${ }^{27,28)}$, approaches to detect deletions should be introduced and developed. Our approach employing the DGGE of PCR-amplified DNA fragments can detect deletions and insertions of less than $15 \mathrm{bp}$. This technique will also detect variations such as deletions and insertions of large DNA fragments of up to several thousands bp and rearrangement in and around the target sequences since those variations will possibly be reflected as loss or change in length of the PCR-products. However, in order to detect a heterozygote for a normal allele and an allele with a deletion, an insertion or a rearrangement (D/I/R) for which loss of the PCR-product is expected, techniques are required not only for quantitative PCR amplification ${ }^{29,30)}$ but also quantitative analysis of the products which can accurately measure loss of intensity of bands by $50 \%$. The occurrence of $D / L / R$ variants was relatively rapidly screened by a modification of the usual restriction enzyme mapping strategy in which each sample was digested with a single combination of two enzymes and the blots were probed with an extensive series of probes ${ }^{31)}$. Variants with $D / 1 / R$ were recognized by appearance of new bands. However, for detection of deletions which removed the totality of single alleles, quantitative analysis for the band intensity is also required except for those deletions in the sex-linked loci in males. The quantitative amplification in the PCR will be developed and quantitative analysis of the PCR-products and the Southern blottings will be performed by using an image analyzer which can measure radioactivity or fluorescence or chemiluminescence of the bands on the gels or filters. The analysis of the PCR-products on twodimensional polyacrylamide gels and two-dimensional $\mathrm{DGGE}^{32,33)}$ have the potential to increase the efficiency of the search for mutations when quantitative as well as qualitative analyses are available by computer assisted image analyzer.

Selection of target sequences will determine the characteristics and value of the study and efficiency with which the study will be carried out. There are two different considerations. The first involves selection of targets which involve functional genes, whether these functions are currently precisely understood or not. In the case where a significant difference in the mutation rates between the children of the A-bomb exposed parents and the control children is observed, this approach should be seriously considered since mutations in the functional genes will be reflected in the quality or the quantity of the gene products and could contribute to mortality or morbidity in the children. However, since the repair of lesions is non-random in the mammalian genom $\mathrm{e}^{34,35)}$, exhibiting a distinct preference for actively transcribed DNA sequences, mutation rates in these sequences should be lower compared to those in the sequences not actively transcribed or in repetitive sequences. This will increase the number of nucleotides to be screened for mutations. On the contrary, the other approach prefers to select the targets from sequences such as repetitive and non-coding sequences where high spontaneous mutation rates have been observed ${ }^{36-38}$, in order to detect a significant difference in the mutation rates between the two groups with a comparatively small number of examinations. However, even though the significant difference in the mutation rates is observed, evaluation of the result in relation to health will be difficult and may be ignored by the public and the scientific societies until the roles of those non-coding 
sequences are recognized as important in human life. We suggest that the main part of the targets should involve functional genes including exons, introns, 5'- and 3'-flanking regions and sequences where regulatory functions are expected to be exist.

We estimated the numerical requirements for the study designed to demonstrate a significant difference between the mutation rates of exposed and control groups. Our recent estimate for the spontaneous mutation rate for nucleotide substitutions in loci encoding for erythrocyte enzymes and serum proteins is $1 \times 10^{-8} /$ nucleotide/generation $^{39)}$. Though the mutation rate for deletion/insertion/rearrangement $(D / 1 / R)$ events for these loci is not known, we assume that it is the same as that for the nucleotide substitutions and the value of $2 \times 10^{-8} /$ nucleotide/generation will be used as the total mutation rate. The average conjoint parental gonad dose for the approximately 13,000 children born to parents receiving $\geqq 0.01 \mathrm{~Sv}$ of the atomic bomb radiation has recently been estimated to be $0.4 \mathrm{~Sv}$ using a system for calculating organ doses termed Dosimetry System $1986(\mathrm{DS} 86)^{40)}$. On the basis of five indicators, that is, untoward pregnancy outcomes, mortality in the live-born children, malignancies in the children, sex-chromosome aneuploids and protein mutations, the most probable gametic doubling dose has been estimated to be between 1.7 and $2.2 \mathrm{~Sv}^{11}$. We will assume that the two parents of the cell line trios have received together on average $1 / 5$ of the doubling dose. From standard power function statistics, we can then calculate that on the assumption of a type I error of 0.05 and a type $\mathrm{II}$ error of 0.20 , it would require two samples of approximately $1.8 \times 10^{10}$ nucleotides surveyed, to demonstrate a significant difference between the mutation rates of the two groups. The number of children in each of the two groups is projected to be approximately 500 and a target sequence of approximately 3,000 nucleotides $(3,000 \times 2$ nucleotides per diploid child) are employed, then some 6,000 target sequences are required to achieve these numbers. Otherwise stated, some $3.6 \times 10^{7}$ nucleotides should be examined for each of the children. When these huge requirements and the tentative estimate of the efficiency of our approach are considered, there is a possibility that the statistic significance will not be obtained for the studies at the DNA level, as for the previous studies, but still the data will be used by combining them with the large corpus of information already available. However, we cannot emphasize too strongly how approximate these calculations are. DNA technologies are evolving so rapidly that any evaluation made today will surely be superceded within the next year or two, to refine the current estimates for the mutation rate and the doubling dose.

\section{REFERENCES}

1. Neel, J.V., Schull, W.J. and Awa, A.A. (1990) The children of parents exposed to atomic bombs: Thoughts on the genetic doubling dose of radiation for humans. Am. J. Hum. Genet. in press.

2. Neel, J.V., Satoh, C., Goriki, K., Asakawa, J., Fujita, M., Takahashi, N., Kageoka, T. and Hazama, R. (1988) Search for mutations altering protein charge and/or function in children of atomic bomb survivors: final report. Am. J. Hum. Genet. 42: 663-676.

3. Satoh, C. and Neel, J.V. (1988) Biochemical mutations in the children of atomic bomb survivors. In "Genetics of Human Tumors in Japan, Gann Monograph on Cancer Research, No. 35', Ed. H. Takebe and J. Utsunomiya, pp. 191-208, Japan Scientific Societies Press, Tokyo, and Taylor and Francis, London and Philadelphia. 
4. Satoh, C., Hiyama, K., Takahashi, N., Kodaira, M. and Neel, J.V. (1989) Approaches to DNA methods for the detection of heritable mutations in humans. Proceedings of the 5th International Conference on Environmental Mutagens (ICEM). July 10-15, Cleveland, Ohio, USA.

5. Takahashi, N., Hiyama, K., Kodaira, M. and Satoh, C. (1990) An improved method for the detection of genetic variations in DNA with denaturing gradient gel electrophoresis. Mutation Res, 234: 61-70.

6. Hiyama, K., Kodaira, M. and Satoh, C. (1990) Detection of deletions, insertions and single nucleotide substitutions in cloned $\beta$-globin genes and new polymorphic nucleotide substitutions in $\beta$-glabin genes in a Japanese population using ribonuclease cleavage at mismatches in RNA:DNA duplexes. Mutation Res. in press.

7. Sheffield, V.C., Cox, D.R., Lerman, L.S. and Myers, R.M. (1989) Attachment of a 40-base-pair G+C-rich sequence (GC-clamp) to genomic DNA fragments by the polymerase chain reaction results in improved detection of single-base changes. Proc. Natl. Acad. Sci. USA 86: 232-236.

8. Myers, R.M., Sheffield, V.C. and Cox, D.R. (1989) Mutation detection by PCR, GC-clamps, and denaturing gradient gel electrophoresis. In "PCR Technology: Principles and Applications for DNA Amplification", Ed. Henry A. Erlich, pp.71-88, Stockton Press, New York, London, Tokyo, Melbourne, Hong Kong.

9. Myers, R.M., Larin, Z. and Maniatis, T. (1985) Detection of single base substitutions by ribonuclease cleavage at mismatches in RNA:DNA duplexes. Science 230: 1242-1246.

10. Myers, R.M. and Maniatis, T. (1986) Recent advances in the development of methods for detecting single-base substitutions associated with human genetic diseases. Cold Spring Harbor Symp. Quant. Biol. 51: 275-284.

11. Myers, R.M., Lumelsky, N., Lerman, L.S. and Maniatis, T. (1985) Detection of single base substitutions in total genomic DNA. Nature 313: 495-498.

12. Lerman, L.S., Silverstein, K. and Grinfeld, E. (1986) Searching for gene defects by denaturing gradient gel electrophoresis. Cold Spring Harbor Symp. Quant. Biol. 51: 285-297.

13. Myers, R.M., Maniatis, T. and Lerman, L.S. (1987) Detection and localization of single base changes by denaturing gradient gel electrophoresis. In "Methods in Enzymology, Vol. 155", Ed. R. Wu, pp.501-527, Academic Press, New York.

14. Noll, W.W. and Collins, M. (1987) Detection of human DNA polymorphisms with a simplified denaturing gradient gel electrophoresis technique. Proc. Natl. Acad. Sci. USA 84: 3339-3343.

15. Cotton, R.G.H., Rodrigues, N.R. and Campbell, R.D. (1988) Reactivity of cytosine and thymine in singlebase-pair mismatches with hydroxylamine and osmium tetroxide and its application to the study of mutations. Proc. Natl. Acad. Sci. USA 85: 4397-4401.

16. Grompe, M., Muzny, D.M. and Caskey, C.T. (1989) Scanning detection of mutations in human ornithine transcarbamoylase by chemical mismatch cleavage. Proc. Natl. Acad. Sci. USA 86: 5888-5892.

17. Fischer, S.G. and Lerman, L.S. (1983) DNA fragments differing by single base-pair substitutions are separated in denaturing gradient gels: Correspondence with melting theory. Proc. Natl. Acad. Sci. USA 80: 1579-1583.

18. Myers, R.M., Fischer, S.G., Maniatis, T. and Lerman, L.S. (1985) Modifications of the melting properties of duplex DNA by attachment of a GC-rich DNA sequence as determined by denaturing gradient gel electrophoresis. Nucleic Acids Res. 13: 3111-3129.

19. Myers, R.M., Fischer, S.G., Lerman, L.S. and Maniatis, T. (1985) Nearly all single base substitutions in DNA fragments joined to a GC-clamp can be detected by denaturing gradient gel electrophoresis. Nucleic Acids Res. 13: $3131-3145$.

20. Takahashi, N., Hiyama, K., Kodaira, M. and Satoh, C. (1988) Detection of mismatches in RNA:DNA duplexes. Report 4, Paper presented at 11 th Meeting of the Japan Molecular Biology Society, Tokyo, 20-23 December.

21. Saiki, R.K., Scharf, S., Faloona, F., Mullis, K.B., Horn, G.T., Erlich, H.A. and Arnheim, N. (1985) Enzymatic amplification of $\beta$-globin genomic sequences and restriction site analysis for diagnosis of sickle cell anemia. Science 230: 1350-1354.

22. Saiki, R.K., Gelfand, D.H., Stoffel, S., Scharf, S.J., Higuchi, R., Horn, G.T., Mullis, K.B. and Eriich, H.A. (1988) Primer-directed enzymatic amplification of DNA with a thermostable DNA polymerase. Science 
239: 487-491.

23. Saiki, R.K. (1989) The design and optimization of the PCR. In "PCR Technology: Principles and Applications for DNA Amplification", Ed. Henry A. Erlich, pp.7-16, Stockton Press, New York, London, Tokyo, Melbourne, Hong Kong.

24. Lerman, L.S. and Silverstein, K. (1987) Computational simulation of DNA melting and its application to denaturing gradient gel electrophoresis. In "Methods in Enzymology, Vol. 155”, Ed. R. Wu, pp.482-501, Academic Press, New York.

25. Gibbs, R.A., Nguyen, P.N., McBride, L.J., Koepf, S.M. and Caskey, C. T. (1989) Identification of mutations leading to the Lesch-Nyhan syndrome by automated direct DNA sequencing of In vitro amplified cDNA. Proc. Natl. Acad. Sci. USA 86: 1919-1923.

26. Kawasaki, E.S. and Wang, A.M. (1989) Detection of gene expression. In "PCR Technology: Principle and Applications for DNA Amplification", Ed. Henry A. Erlich, pp.89-97, Stockton Press, New York, London, Tokyo, Melbourne, Hong Kong.

27. Yandell, D.W., Dryja, T.P. and Little, J.B. (1986) Somatic mutations at a heterozygous autosomal locus in human cells occur more frequently by allele loss than by intragenic structural alterations. Somatic Cell Mol. Genet. 12: 255-263.

28. Liber, H.L., Call, K.M. and Little, J.B. (1987) Molecular and biochemical analyses of spontaneous and X-ray-induced mutants in human lymphoblastoid cell. Mutation Res. 178: 143-153.

29. Chelly, J., Kaplan, J.C., Maire, P., Gautron, S. and Kahn, A. (1988) Transcription of the dystrophin gene in human muscle and non-muscle tissues. Nature 333: 858-860.

30. Chelly, J., Hamard, G., Koulakoff, A., Kaplan, J.C., Kahn, A. and Berwald-Netter, Y. (1990) Dystrophin gene transcribed from different promoters in neuronal and glial cells. Nature 344: 64-65.

31. Mohrenweiser, H.W., Larsen, R.D. and Neel, J.V. (1989) Development of molecular approaches to estimating germinal mutation rates. 1 . Detection of insertion/deletion/rearrangement variants in the human genome. Mutation Res. 212: 241-252.

32. Fischer, S.G. and Lerman, L.S. (1979) Two-dimensional electrophoresis separation of restriction enzyme fragments of DNA. In "Methods in Enzymology, Vol. 68", Ed. R. Wu, pp.183-191, Academic Press, New York.

33. Uitterlinden, A.G., Slagboom, P.E., Knook, D.L. and Vijg, J. (1989) Two-dimensional DNA fingerprinting of human individuals. Proc. Natl. Acad. Sci. USA 86: 2742-2746.

34. Mellon, I., Bohr, V.A., Smith, C.A. and Hanawalt, P.C. (1986) Preferential DNA repair of an active gene in human cells. Proc. Natl. Acad. Sci. USA 83: 8878-8882.

35. Hanawalt, P.C. (1989) Preferential repair of damage in actively transcribed DNA sequences in vivo. Genome 31: $605-611$.

36. Jeffreys, A.J., Royle, N.J., Wilson, V. and Wong, Z. (1988) Spontaneous mutation rates to new length alleles at tandem-repetitive hypervariable loci in human DNA. Nature 332: 278-281.

37. Kovacs, B.W., Shahbahrami, B. and Comings, D.E. (1989) Studies of human germinal mutations by deoxyribonucleic acid hybridization. Am. J. Obstet. Gynecol. 160: 798-804.

38. Armour, J.A.L., Patel, I., Thein, S.L., Fey, M.F. and Jeffreys, A.J. (1989) Analysis of somatic mutations at human minisatellite loci in tumors and cell lines. Genomics 4: 328-334.

39. Neel, J.V., Satoh, C., Goriki, K., Fujita, M., Takahashi, N., Asakawa, J. and Hazama, R. (1986) The rate with which spontaneous mutation alters the electrophoretic mobility of polypeptides. Proc. Natl. Acad. Sci. USA 83: 389-393.

40. Woolson, W.A., Egbert, S.D., Gritzner, M.L. (1987) Dosimetry system 1986. In "U.S.-Japan Joint Reassessment of Atomic Bomb Radiation Dosimetry in Hiroshima and Nagasaki, Vol. 1", Ed. William C. Roesch, pp.405-431, Radiation Effects Research Foundation. 